\title{
Distance as an influence on demand in general practice
}

\author{
DAVID PARKIN \\ From the Department of Economics, University of York
}

SUMMARY A survey of general practice in the London borough of Lambeth was analysed to discover how the distance from a patient's home to a medical facility affects the utilisation of that facility. It was shown that distance has a negative effect on utilisation for all population groups except men aged 15 to 64. The effect was especially marked for women, for the elderly, and for Social Classes III, IV, and V, which are the groups with the highest utilisation rates. Some diagnostic groups singled out for analysis showed the same effect. These results are related to other studies and to an economic theory seeking to explain patterns of demand.

In a study of general practice reported by Morrell, Gage, and Robinson (1970), the consultation rate of patients in that practice was inversely related to the distance from the patients' homes to the doctors' surgery. As part of a wider study of the impact of accessibility, in terms of time and distance, on the utilisation of medical facilities, this paper reports a secondary analysis of the original survey data carried out with the co-operation of the authors.

The authors reported that the consultation rate in the practice fell from 5.0 consultations per head of population per year for patients living less than five-eighths of a mile from the surgery to 3.6 consultations for those living at greater distances. The proportion of consultations taking place in the home also fell over the same distances, from $9 \cdot 7$ per cent to $6 \cdot 1$ per cent. Further tests ruled out the possibility that these observed differences might reflect differences in the numbers of patients in each age, sex, or social class group in the area.

The purpose of the secondary analysis was to establish whether or not the effect of distance on utilisation was significant for all sections of the population and whether or not the effect was uniform.

\section{Data and methods}

A more detailed description of the collection and verification of the data, and general details of the pattern of demand in the practice population, can be found in the original report. Every consultation, defined as 'any occasion on which a patient receives professional advice or help or treatment from his doctor', was recorded over a period of time. Each record consisted of information on the patient (age, sex, distance lived from surgery, and details of the particular consultation-date, place, and diagnosis).
The base population, or population at risk, was estimated. For the purposes of the secondary analysis, all data from the year 1968 were used.

Distances from the surgery to the patient's home were divided into Zone 1 (under 0.25 of a mile); Zone 2 (0.25 to 0.625 of a mile); and Zone 3 (over $\mathbf{0 . 6 2 5}$ of a mile). Ages were grouped into 0-14; 15-64; and 65 and over. Social Classes I and II were grouped together, as were Social Classes III, IV, and V.

The consultation rate was defined as the number of consultations taking place during the year divided by the total practice population (including those who did not consult at all during the year). The attendance rate was the number of consultations divided by the population who actually did consult during the year.

The referral rate was defined as the number of referrals to hospital per consulting patient. Each of these rates was analysed separately for distance zones, sex and age groups, and social class aggregates.

Consultation rates for some selected diagnoses were treated similarly. For technical reasons, it was not possible to consider a breakdown of the population by all of the group variables simultaneously-distance, age, sex, and social classfor analysis by consultation rates, although this was possible for the attendance rate.

\section{Results}

The results of these analyses are set out in Tables 1 and 2. It was found that most of those in the intermediate distance group did not have rates significantly different from the group living nearest to the surgery. Hence, except for one group, the 
Table 1 Consultation rates by distance and age, sex, and social class groups

\begin{tabular}{|c|c|c|c|c|}
\hline \multirow[b]{2}{*}{ Population group } & \multicolumn{4}{|c|}{ Consultation rate } \\
\hline & Overall & Zone 1 & Zone 2 & Zone 3 \\
\hline \multirow{2}{*}{$\begin{array}{l}\text { Whole population } \\
\text { Males } \\
\text { Females } \\
\text { Social Classes I and II } \\
\text { Social Classes III, IV, V } \\
\text { Age groups (years) } \\
\text { 0-14 (male) } \\
0-14 \text { (me) } \\
0-14 \text { (female) } \\
15-64 \text { (male) } \\
15-64 \text { (male) } \\
15-64 \text { (female) } \\
\text { Over } 64 \text { (a) } \\
\text { Over } 64 \text { (male) } \\
\text { Over } 64 \text { (female) (b) }\end{array}$} & $\begin{array}{l}4 \cdot 82 \\
4 \cdot 17 \\
5 \cdot 40 \\
4 \cdot 14 \\
4 \cdot 88\end{array}$ & $\begin{array}{l}5 \cdot 07^{* * *} \\
4 \cdot 17^{* * *} \\
5 \cdot 89^{* * *} \\
4 \cdot 29^{* * *} \\
5 \cdot 14^{* * *}\end{array}$ & $\begin{array}{l}5 \cdot 18 * * * \\
4 \cdot 80^{* * *} \\
5 \cdot 53^{* * *} \\
4 \cdot 98^{* * *} \\
5 \cdot 21^{* * *}\end{array}$ & $\begin{array}{l}3 \cdot 53 \\
3 \cdot 37 \\
3 \cdot 67 \\
2 \cdot 45 \\
3 \cdot 63\end{array}$ \\
\hline & $\begin{array}{l}4 \cdot 37 \\
4 \cdot 18 \\
4 \cdot 55 \\
4 \cdot 49 \\
3 \cdot 73 \\
5 \cdot 22 \\
7 \cdot 33 \\
7 \cdot 08 \\
7 \cdot 49\end{array}$ & $\begin{array}{l}4 \cdot 55^{* * *} \\
4 \cdot 16^{* * *} \\
4 \cdot 90^{* * *} \\
4 \cdot 55^{* * *} \\
3 \cdot 57 \\
5 \cdot 52^{* * *} \\
8 \cdot 67^{* * *} \\
8 \cdot 20^{* * *} \\
8 \cdot 97^{* * *}\end{array}$ & $\begin{array}{l}4 \cdot 87 * * * \\
5 \cdot 17 * * * \\
4 \cdot 59 * * * \\
4 \cdot 94^{* * *} \\
4 \cdot 33 \\
5 \cdot 52 * * * \\
6 \cdot 96 * * * \\
6 \cdot 75^{* * *} \\
7 \cdot 12^{* * *}\end{array}$ & $\begin{array}{l}3 \cdot 13 \\
2 \cdot 88 \\
3 \cdot 35 \\
3 \cdot 69 \\
3 \cdot 46 \\
3 \cdot 91 \\
3 \cdot 34 \\
3 \cdot 86 \\
3 \cdot 02\end{array}$ \\
\hline
\end{tabular}

Significant differences are from distance group 3.

$* \mathrm{P}<0.05$.

$* * \mathrm{P}<0.025$

$* * \mathrm{P}<0.001$

In addition, the differences between distance groups 1 and 2 are statistically significant for population group (a) $\mathrm{P}<0.01$ and for population group $(b) \mathrm{P}<0.05$.

Table 2 Attendance rates by distance and age, sex, and social class groups

\begin{tabular}{|c|c|c|c|c|}
\hline \multirow[b]{2}{*}{ Population group } & \multicolumn{4}{|c|}{ Attendance rate } \\
\hline & Overall & Zone 1 & Zone 2 & Zone 3 \\
\hline \multirow{4}{*}{$\begin{array}{l}\text { Whole population } \\
\text { Males } \\
\text { Females } \\
\text { Social Classes I and II } \\
\text { Social Classes III, IV. V } \\
\text { Age groups (years) } \\
\text { 0-14 (male) } \\
0-14 \text { (male) } \\
0-14 \text { (female) } \\
15-64 \text { (male) } \\
\text { 15-64 (male) } \\
15-64 \text { (female) } \\
\text { Over } 64 \text { (male) } \\
\text { Over } 64 \text { (male) } \\
\text { Over } 64 \text { (female) } \\
15-64 \text { male } \\
\text { Social Classes I } \\
\text { and II } \\
\text { 15-64 male, } \\
\text { Social Classes III, } \\
\text { IV, V }\end{array}$} & $\begin{array}{l}6 \cdot 12 \\
5 \cdot 50 \\
6 \cdot 64 \\
4 \cdot 59 \\
6 \cdot 31\end{array}$ & $\begin{array}{l}6 \cdot 29 * * * \\
5 \cdot 52 \\
6 \cdot 93^{* * *} \\
4 \cdot 42 \\
6 \cdot 53^{* * *}\end{array}$ & $\begin{array}{l}6 \cdot 09 * * \\
5 \cdot 73 \\
6 \cdot 42 \\
5 \cdot 08 \\
6 \cdot 25 * *\end{array}$ & $\begin{array}{l}5 \cdot 46 \\
5 \cdot 09 \\
5 \cdot 82 \\
4 \cdot 28 \\
5 \cdot 56\end{array}$ \\
\hline & $\begin{array}{l}5 \cdot 16 \\
4 \cdot 81 \\
5 \cdot 50 \\
5 \cdot 97 \\
5 \cdot 32 \\
6 \cdot 52 \\
8 \cdot 48 \\
7 \cdot 87 \\
8 \cdot 90\end{array}$ & $\begin{array}{l}5 \cdot 24 * \\
4 \cdot 70 \\
5 \cdot 77 \\
6 \cdot 07 \\
5 \cdot 24 \\
6 \cdot 74 \\
8 \cdot 87 * * \\
8 \cdot 48 * * \\
9 \cdot 11\end{array}$ & $\begin{array}{l}5 \cdot 35^{*} \\
5 \cdot 36^{*} \\
5 \cdot 33 \\
5 \cdot 96 \\
5 \cdot 52 \\
6 \cdot 34 \\
8 \cdot 16 \\
7 \cdot 51 \\
8 \cdot 70\end{array}$ & $\begin{array}{l}4 \cdot 50 \\
4 \cdot 24 \\
4 \cdot 73 \\
5 \cdot 63 \\
5 \cdot 27 \\
5 \cdot 97 \\
6 \cdot 69 \\
5 \cdot 72 \\
7 \cdot 74\end{array}$ \\
\hline & $4 \cdot 64$ & $4 \cdot 44$ & $5 \cdot 29$ & $4 \cdot 30$ \\
\hline & $5 \cdot 99$ & $6 \cdot 16^{* *}$ & $5 \cdot 95$ & $5 \cdot 34$ \\
\hline
\end{tabular}

Significant differences are from distance group 3.

P $<0.05$

**P $<<0.025$

$* * * \mathrm{P}<0.01$

differences between them have been ignored in the significance tests. All but one group (men aged 15-64) showed significantly lower consultation rates for the furthest distance zone. For attendance rates, it is apparent that distance has an effect only on those groups whose consultation and attendance rates are relatively high: namely, females, the elderly, and those in Social Classes III, IV, and V. The elderly are further characterised by significant differences between the consultation rates of the nearest, intermediate, and furthest distance zonesthe clearest negative effect of distance on utilisation to emerge. Further tests showed similar results both for consultations initiated by patients, whether for a new symptom or an old symptom, and consultations initiated by doctors.

Consultation rates were computed for different diagnoses, but the results are not reported in detail here. However, for all the diagnoses selected for analysis, consultation rates were significantly lower in the furthest distance group. These diagnoses were: acute respiratory conditions; chronic respiratory conditions; accidents; and mental disorder. Within these groups, distance does not appear to have an effect on the consultation rate for men diagnosed as accidents, or on the consultation rate for Social Classes I and II diagnosed as mental disorder.

Referral rates (again, not reported in detail here) were not found to differ significantly between distance groups, except for women aged 15-64, in whom the rates were 0.21 referrals per consulting person for the nearest group, and $0 \cdot 12$ for the furthest group.

\section{Discussion}

The results presented here show that patterns of demand differ for the different distance zones. It may be argued that the differences might not be directly related to distance, and, unfortunately, distance was not originally measured by the researchers as a continuous variable, so a direct correlation of distance and demand is not possible. However, there is no evidence to suggest that the population or environment of the various distance zones differed in ways which might have the sort of effect on demand patterns that was observed. Therefore, I suggest that the distances from patients' homes to the surgery did deter the population both from consulting at all with the doctor, and also from attending frequently. Moreover, the doctors were apparently sensitive to the distances that their patients, and they themselves, had to travel. However, this was not true of men aged 15-64, for whom neither consultation rates nor attendance rates decreased significantly with increased distance; for those in Social Classes I and II in particular, attendance rates were not affected by distance. Men aged 15-64 are likely to work outside their homes, so their point of reference for decisions about consultations may not be the home but the workplace, or how close the surgery is to the nearest point on the route they take for the journey to or from work. Furthermore, the cost to them of the time taken by their journey to the surgery, and the cost of transport io the surgery, may not be so significant a part of the total costs that are relevant when a decision to consult or not to consult 
is made on some specific occasion; costs which involve loss of earnings may be more important. Similarly, for Social Classes I and II, journey time costs and travel costs may be relatively less important than other costs because of higher income or greater car ownership.

It may be observed that the distance effect appears to be most marked in those groups who consult most. Apparently, the other groups are deterred by distance from consulting in the first place, but are not deterred from making as many consultations, except for men aged 15-64. A differential in the effect may also be observed by comparison of the relative sizes of the consultation rates for various population groups between distance zones. In general, the higher the overall consultation rate, the greater the rate at which consultations diminish over distance. This can be seen by comparing the elderly, the group who consult most frequently, with the rest of the population. The consultation rate is nearly twice as high for the elderly compared with the group aged 15-64 in the nearest distance zone, but in the furthest zone it is actually lower. A comparison between the age/sex groups with the highest and lowest consultation rates (men aged 15-64 and women over 64) is even more marked.

For different diagnoses, the results seem to show that the effect of distance is quite pervasive, occurring as it does over both acute and chronic states, both mental and physical disorders, and accidents. For the latter diagnosis, it may be that the effect does not exist for men, since the majority of accidents may occur at the workplace, and not at home.

Although the differences between distance zones appear to be of significant size, it is necessary to evaluate their importance. As a preliminary, we may assume that the incidence of sickness, etc., is homogeneous in this population with respect to distance. The interpretation of differences in the consultation and attendance rates depends crucially on how the need for consultations is interpreted. The patients' behaviour reveals that they perceived the existence of problems of inaccessibility to the practice, and those sub-groups of the population who, in general, perceived most need for consultations were most affected by such problems. It may be argued that, from a medical standpoint, the differences in demand between sub-groups of the population might not represent differences in sickness, etc., so that the problem of inaccessibility might not necessarily be thought to be worse for those who perceive most need. It may also be argued that the differences in demand between distance groups might not represent differences in sickness treated, and that, if so, inaccessibility is not really a problem at all. From the point of view of society, the questions of whether or not these results indicate a problem of inaccessibility, and, if they do, the extent of the problem, both depend on the value placed on the marginal consultations. We need to ask, for example: 'What value is to be placed on the extra one-and-a-half consultations enjoyed by the population closest to the surgery?' and 'What relative valuations are to be given to the extra 0.9 consultations enjoyed by the group aged 15-64 in the nearest zone, and the extra $5 \cdot 3$ consultations of those in the group aged over 64 in the nearest zone, compared with their respective contemporaries in the furthest zone?'

The results conform very closely to the kind of patterns of observed behaviour that economic theory predicts and that other studies have shown to occur. The effect of distance has been well researched in the United States of America (Shannon et al., 1969), and some research into the joint effect of social class and distance was reported by Weiss and Greenlick (1970) for medical facilities in Portland, Oregon. Their research showed that distance and social class jointly affected the point of contact with the medical care system-substituting, for example, telephone calls to the doctor for personal contact as distance increases.

Research in the United Kingdom has been sporadic. Some references may be found in Glass (1974) and there are also the findings of Dixon and Morris (1971). Glass also details an elementary description of an economic theory which seeks to explain the effect of distance and time on utilisation of medical facilities. A more detailed and mathematical treatment of this economic problem is given in, for example, Acton (1975). It relies on the use of time and travel costs as a price which must be paid by a patient in order to seek care, which makes it possible to construct a 'demand curve', in this case for health care, which by hypothesis is a negative relationship between price (time and travel) and demand (utilisation). We may observe that the demand curve will differ from individual to individual given the different cost of time to the individual reflecting different alternative uses of time. For example, if there are alternative uses yielding greater income (or utility) a higher cost of time would be expected and hence low utilisation.

The advantage of the economic approach is that it permits some quantification of the benefits perceived by the patient to arise from consultations. We may consider the price (in terms of time and travel costs) which the 'consumer' (that is, the patient) is willing to pay in order to 'consume' health care (that is, to consult) as the marginal valuation of those consultations; that is, the value of an extra consultation to the patient. If we had 
information on the value of time for each age/sex group, we could utilise a type of analysis used in the economics of recreation, sometimes called the Clawson method of estimating demand curves (Williams and Anderson, 1975). This would make it possible to estimate the changes in the benefits accruing to patients as a result of varying the site of a medical facility.

The relationship reported here seems also to be of some quantitative significance in evaluating the likely effects on utilisation of the current trend towards grouping practices together in shared premises, since this is likely, on balance, to increase the distances that patients have to travel to gain access to medical facilities. This is especially important because those groups most at risk appear to be the most sensitive to the effect of distance.

I thank Professor Alan Williams of the Department of Economics, University of York, Professor D. Morrell of the General Practice Teaching and Research Unit, St. Thomas's Hospital Medical School, and Mr. Alan Rawe. The research was supported by the Social Science Research Council.

Reprints from David Parkin, Department of Social
Research, University Hospital of South Manchester, Manchester M20 9BX.

\section{References}

Acton, J. P. (1975). Non-monetary factors in the demand for medical services: some empirical evidence. Journal of Political Economy, 83, 595-614.

Dixon, P. N., and Morris, A. F. (1971). Casual attendances at an accident department and a health centre. British Medical Journal, 4, 214-215.

Glass, N. (1974). The economics of general practice in England. British Journal of Preventive and Social Medicine, 28, 207-209.

Morrell, D. C., Gage, H. G., and Robinson, N. A. (1970). Patterns of demand in general practice. Journal of the Royal College of General Practitioners, 19, 331-342.

Shannon, G. W., Bashshur, R. L., and Metzner, C. A. (1969). The concept of distance as a factor in accessibility and utilisation of health care. Medical Care Review, 26, 143-161.

Weiss, J. E., and Greenlick, M. R. (1970). Determinants of medical care utilisation: the effect of social class and distance on contacts with the medical care system. Medical Care, 8, 456-462.

Williams, A., and Anderson, R. (1975). Efficiency in the Social Services. Basil Blackwell and Martin Robertson: Oxford and London. 